\title{
Aktif özofagus varis kanamasının kontrolünde farmakolojik tedavi ve endoskopik band ligasyonu kombinasyonunun etkinliği
}

\author{
Efficiency of somatostatin plus endoscopic band ligation in the treatment of acute variceal hemorrhage
}

Mustafa ÇELIK, Emrah ALPER, Zafer BUYRAÇ, Mahmut ARABUL, Altay KANDEMIR, Fatih ASLAN, Nafi YAZICIOĞLU, Belkıs ÜNSAL

Atatürk Eğitim ve Araştırma Hastanesi Gastroenteroloji Kliniği, Izmir

Giriş ve Amaç: Bu çalışmada akut özofagus varis kanaması ile hastaneye başvuran hastalarda farmakolojik ve endoskopik tedavi kombinasyonunun etkinliği değerlendirildi. Gereç ve Yöntem: Çalışma Izmir Atatürk Eğitim ve Araştırma Hastanesi Gastroenteroloji Kliniğinde retrospektif olarak yapıldı. Ocak 2008- Haziran 2010 tarihleri arasında akut özofagus varis kanaması düşünülerek somatostatin tedavisi başlanan ve üst gastrointestinal sistem endoskopisi sonrası aktif özofagus varis kanaması saptanarak, endoskopik band ligasyonu yapılan hastalar değerlendirildi. Bulgular: Aktif özofagus varis kanamasi saptanan 43 hastanın 41 'inde (\%95) endoskopik tedavi ile kanama kontrolü sağlandi. Somatostatin ve endoskopik tedavi kombinasyonu ile 5 hastada (\%11,7) kanama tekrarı (Hgb düşüşü, melena, hematemez) saptand. Kanama tekrarı saptanan 3 hastada Sengstaken balon tamponadı sonrasinda ikinci kez endoskopik tedavi yapıldı ve kanama kontrol altına alındı. Ancak 2 hasta yapılan tüm girişimlere rağmen kaybedildi. Hastalarda işleme bağlı ciddi komplikasyon (kanamanın şiddetlenmesi, perforasyon, aspirasyon) saptanmadı. Sonuç: Sonuç olarak bu çalıșmada akut varis kanaması düşünülen hastalara ön tanı konulduğu andan itibaren farmakolojik tedavi başlanması ve 12 saat içinde endoskopik tedavi ile endoskopik tedavi yapılmasinın etkin ve güvenilir bir tedavi yaklaşımı olduğu saptandı.

Anahtar kelimeler: Varis kanaması, band ligasyonu, somatostatin

\section{GÍRIS}

Siroz hastalarında akut gastrointestinal sistem kanamaları hızlı ve dikkatli yaklaşım gerektiren acil bir durumdur. Bu nedenle akut varis kanaması düşünülen hastalar takip ve tedavi konusunda yeterli donanıma sahip merkezlere refere edilmelidir. Akut varis kanamasının tedavisine yönelik güncel yaklaşımların yaşam süresi üzerinde olumlu katkısı olduğunu destekleyen yayınlar mevcuttur (1-2). Akut varis kanamasına genel yaklaşımda volüm replasmanı dikkat gerektiren bir durumdur. Hemodinamik stabilitenin sağlanması ve hemoglobin düzeyinin yaklaşık $8 \mathrm{~g} / \mathrm{dL}$ düzeyinde tutulması önerilir (3). Ayrica siroz hastalarının gastrointestinal sistem kanamalarında kısa süreli proflaktik antibiyotik kullanımının bakteriyel enfeksiyon riskini azalttığı ve yaşam süresi üzerinde olumlu etkisi olduğu düşünülmektedir (4-5). Bu yaklaşımların yanında varis kanamalarının kontrolünde ve erken rekürrensin önlenmesine yönelik spesifik önlemler de mevcuttur. Akut varis kanamasına yönelik farmakolojik tedavi varis kanaması düşünüldüğü anda, hatta üst gastrointestinal sistem (GIS) endoskopisinden önce bile başlanabilir. Acil skleroterapi ve far-
Background and Aims: In this study, we evaluated the efficiency of somatostatin plus endoscopic band ligation in the treatment of acute variceal hemorrhage. This study was performed retrospectively in the Gastroenterology Department, Izmir Atatürk Research and Training Hospital. We evaluated the patients who presented to the emergency service with the symptoms of acute variceal hemorrhage between January 2008 and June 2010. We succeeded in controlling bleeding in 41 (95\%) of 43 patients with somatostatin and endoscopic band ligation combination. Rebleeding rate was determined as $11.7 \%$. We showed that somatostatin and endoscopic band ligation combination therapy is effective and safe in the treatment of acute variceal hemorrhage.

Key words: Variceal hemorrhage, band ligation, somatostatin

makolojik tedaviyi (vazopressin \pm nitrogliserin, terlipressin, somatostatin, oktreotid) karşılaştıran 15 çalışmayı kapsayan bir meta-analizde benzer etkinlik gösterilmiştir (6). Akut varis kanamasının tedavisinde farmakolojik ve endoskopik tedavinin birlikte uygulanması en uygun seçenek olarak görülmektedir. 8 çalışmanın değerlendirildiği bir meta-analizde akut varis kanamasinda endoskopik tedavi [(skleroterapi veya endoskopik band ligasyonu (EBL)] ile endoskopik, farmakolojik tedavi kombinasyonu karşılaştırılmıştır. Endoskopik, farmakolojik tedavi kombinasyonunun kanama kontrolü ve tekrarlama riski açısından daha üstün olduğu görülmüştür (7).

Bu çalışmada akut özofagus varis kanaması ile hastaneye başvuran hastalarda farmakolojik ve EBL kombinasyonunun etkinliğini değerlendirdik.

\section{GEREC ve YÖNTEMLER}

Çalışma Izmir Atatürk Eğitim ve Araştırma Hastanesi Gastroenteroloji Kliniğinde retrospektif olarak yapıldı. Ocak 2008- 
Haziran 2010 tarihleri arasında karaciğer sirozu tanılı olan ve/ veya yeni tanı alan aktif özofagus varis kanama bulguları (hematemez-melena-hematokezya, takip sırasında Hgb düzeyinde en az 2 g/dL düşme) ile acil servise başuran hastalar değerlendirildi.

Hastalara akut varis kanaması ön tanısı konulduktan sonra acil serviste somatostatin tedavisi (250 ug IV bolus sonrasinda 250 ug/saat sürekli infüzyon) başlandı. Hastaların tamamına 12 saat içinde üst GİS endoskopisi yapıldı ve aktif kanaması olup (sızıntı yada fışkırır tarzda kanama) varis kanama odağı saptanan hastalara EBL yapıldı ve somatostatin tedavisi en az 3 gün devam edildi. Endoskopik incelemede aktif kanama saptanmamasına rağmen üzerinde kanama işareti bulunan varisleri olan hastalar medikal tedavi ile tedavi edildi ve EBL ile varis eradikasyon programına alındı. Endoskopik incelemede aktif kanama bulgusu saptanmayan hastaların somatostatin tedavileri kesildi ve 48 saat izlendi. Aktif kanaması olup EBL sonrası takibe alınan hastaların takipleri sırasında 2 gr/dL üzerinde hemoglobin düşüşü, hematemez, melena, hematokezya olması kanama tekrarı olarak kabul edildi. Kanama tekrarı düşünülen hastalara medikal tedaviye ek olarak endoskopik tedavi (EBL) ve/ veya Sengstaken balon tamponadı sonrası endoskopik tedavi uygulandı. Varis kanaması düşünülerek endoskopi yapılan ancak kanama nedeni olarak diğer sebepler saptanan (gastrik ya da duodenal ülser, üst GIS malignitesi vb) hastalar çalışmaya dahil edilmedi.

Hastaların demografik, laboratuvar ve tedavi ile ilgili verileri hastane bilgi işlem veri tabanından, endoskopik verileri endoskopi laboratuvarı kayıtlarından elde edildi.

\section{BULGULAR}

Akut varis kanaması ön tanısı ile acil serviste değerlendirilen 155 hastaya 12 saat içinde üst GIS endoskopisi yapıldı. Varis kanaması düşünülen 155 hastanın yaş ortalaması 58.7 (min 25, max 92) idi. Hastaların 102'si (\%66) erkekti. 43 (\%27,7) hastada sızıntı ya da fişkırır tarzda aktif varis kanaması izlenirken, 99 hastada (\%63.8) portal hipertansiyon bulguları olmasına rağmen (özöfagus- kardia- fundus varisleri yada portal gastropati) aktif varis kanaması izlenmedi. 10 (\%6) hastada kanama sebebi olarak diğer sebepler (duodenum, gastrik ülser) saptandı. 3 hastada ise yoğun kan nedeni ile kanama odağı görülemedi ve hasta işlemi tolere edemediği için ve aspirasyon riski nedeni ile endoskopik tedavi denenmedi. Kanama görülen 43 hastanın yaş ortalaması 61.2 (min 27, max 90) idi ve 32'si (\%74) erkekti. Bu hastaların geliş ortalama Hgb değeri $8.2 \mathrm{mg} / \mathrm{dl}( \pm 3.2)$, Htc değeri $24.3( \pm 9.5)$, Plt değeri 125000 ( $\min 45000 \max 280000$ ) saptandı. Hastaların 5 tanesinin Child pugh skoru A, 28'inin B, 9'unun C idi. Hastaların 13'ü etanole bağlı karaciğer sirozu, 8'i HDV'ye bağlı karaciğer sirozu, 9'u HCV'ye bağlı karaciğer sirozu, 7 hasta kriptojenik, 1 hasta non alkolik steato hepatit, 1 hasta otoim- mün hepatit, 3 hasta primer biliyer siroza bağlı karaciğer sirozu idi. 1 hastada ise ekstrahepatik portal hipertansiyon mevcuttu. Hastaların endoskopik değerlendirmesi kanama s1rasında olduğu için varisleri derecelendirilmedi.

Aktif varis kanaması izlenen hastaların tamamına EBL yapıldı. İslemler sırasında ortalama atılan band sayısı 4.5 (min 1, max 8) idi.

Aktif varis kanaması izlenen 43 hastanın 4l'inde (\%95) EBL ile kanama kontrolü sağlandı. Somatostatin ve EBL kombinasyonu ile 38 hastada $(\% 88,3)$ kanama tekrarı saptanmadı ve hastalar endoskopik ve medikal tedavi sonrası 5 . günde taburcu edildi. Hastaların 5'inde (\%11,7) kanama tekrarı (Hgb düşüşü, melena, hematemez) saptandı. Kanama tekrarı saptanan 3 hastada Sengstaken balon tamponadı sonrasında ikinci kez EBL yapıldı ve kanama kontrol altına alındı. Ancak 2 hasta yapılan tüm girişimlere rağmen kaybedildi.

\section{TARTISMA}

Akut varis kanaması yüksek morbidite ve mortalitesi nedeni ile hızlı ve dikkatli yaklassılması gereken acil bir durumdur. Hastalara yakın takip ve dikkatli volüm replasmanı yapılmalıdır. Varis kanaması düşünüldüğü anda hastalara farmakolojik tedavi (somatostatin ve analogları) başlanmalıdır ve 12 saat içinde üst GIS endoskopi ve tedavi planlanmalıdır (3). Endoskopik tedavi yöntemlerini değerlendiren 10 randomize kontrollü çalışmayı değerlendiren bir meta-analizde ise şu sonuca varılmıştır. Toplam 404 hastada, aktif kanama kontrolünde EBL skleroterapiye göre belirgin düzeyde daha etkin bulunmuştur (toplu rölatif risk 0.53 ve güven aralığı 0.28 1.01) (8). Başka bir çalışmada akut varis kanamasının endoskopik tedavisinde EBL'nin tercih edilmesi ve skleroterapinin EBL'nin teknik olarak mümkün olmadığı hastalarda kullanılması önerilmiştir (3).

Yan etkisi az olan farmakolojik ajanların 5 güne kadar kullanılabiliyor olması, kanama tekrar riskinin en fazla olduğu bu peryotta hastalara tedavi imkanı sağlar. Aktif kanamada somatostatin ve skleroterapiyi karşılaştıran randomize bir çalışmada kanama kontrol oranı (\%80'e karşı \%83), tekrar kanama oranı (\%25'e karşı \%17) bulunmuştur (9). Kanama kontrolü ve tekrar kanamanın önlenmesinde farmakolojik tedavi ve skleroterapi kombinasyonu ise tek başına farmakolojik tedavi ve somatostatin tedavisine göre daha üstün bulunmuştur (10-11).

EBL ve farmakolojik tedavi kombinasyonuna yönelik çeşitli çalışmalar yapılmış ve kombinasyon tedavisinin tek başına EBL'den üstün olduğu görülmüştür (7-12). 100 hastalı bir çalışmada EBL ile oktreotid kombinasyonu, tek başına EBL ile karşılaştırılmıştır. Bu çalışmada EBL ve oktreotid kombinasyonu ile 47 hastanın 45'inde kanama kontrolü sağlanırken, EBL grubunda 47 hastanın 44'ünde kanama kontrolü sağlanmıştır. Aynı çalışmada tekrar kanama oranı kombinasyon 
grubunda \%9, EBL grubunda \%38 bulunmuştur (13). Bir başka çalışmada ise band ligasyonu ile hemostazın sağlanma oranı \%86 olarak bildirilmiştir (14). Çalışmamızda hastalara başvuru sonrası standart dozda somatostatin tedavisine başladik. Medikal tedavi devam ederken endoskopik inceleme ve gereğinde EBL uyguladık. EBL sonrası en az 3 gün somatostatin tedavisine devam ettik. Diğer çalışmalara benzer şekilde EBL ile hastalarımızın \%95'inde kanama kontrolü sağladık ve somatostatin, EBL kombinasyonu ile tekrar kanama oranını $\% 11,7$ saptadik.

İşleme bağlı komplikasyonlar açısından literatüre bakıldığında ülserasyon, striktür oluşumu, perforasyon, mediastinit, as-

\section{KAYNAKLAR}

1. Carbonell N, Pauwels A, Serfaty L, et al. Improved survival after variceal bleeding in patients with cirrhosis over the past two decades. Hepatology 2004; 40: 652-9

2. Chalasani N, Kahi C, Francois F, et al. Improved patient survival after acute variceal bleeding: a multicenter, cohort study. Am J Gastroenterol 2003; 98: 653-9.

3. de Franchis R. Evolving consensus in portal hypertension report of the Baveno IV consensus workshop on methodology of diagnosis and therapy in portal hypertension. J Hepatol 2005; 43: 167-76.

4. Bernard B, Grange JD, Khac EN, et al. Antibiotic prophylaxis for the prevention of bacterial infections in cirrhotic patients with gastrointestinal bleeding: a meta-analysis. Hepatology 1999; 29: 1655-61.

5. Soares-WeiserK, BrezisM, Tur-KaspaR, LeiboviciL. Antibiotic prophylaxis for cirrhotic patients with gastrointestinal bleeding (Cochrane Review). Cochrane Database Syst Rev. 2002; (2): CD002907.

6. D’Amico G, Pietrosi G, Tarantino I, Pagliaro L. Emergency sclerotherapy versus vasoactive drugs for variceal bleeding in cirrhosis: a Cochrane meta-analysis. Gastroenterology 2003; 124: 1277-91.

7. Banares R, Albillos A, Rincon D, et al. Endoscopic treatment versus endoscopic plus pharmacologic treatment for acute variceal bleeding: A meta-analysis. Hepatology 2002; 35: 609-15. pirasyon ve aspirasyona bağlı sepsis tanımlanmıştır. Bir çalışmada komplikasyon oranları EBL'de skleroterapiye göre belirgin olarak daha düşük saptanmıştır (\%2'ye karşı \%22) (13). Hastalarımızda işleme bağlı ciddi komplikasyon (kanamanın şiddetlenmesi, perforasyon, aspirasyon) saptamadık.

Bu çalışmada akut varis kanaması düşünülen hastalara ön tanı konulduğu andan itibaren farmakolojik tedavi başlanması ve 12 saat içinde EBL ile endoskopik tedavi yapılmasının etkin ve güvenilir bir tedavi yaklaşımı olduğunu saptadık. Akut varis kanaması düşünülen hastaların tedavi ve takibinin endoskopik tedavi uygulanabilecek merkezlerde yapılması gerektiğini düşünmekteyiz.

8. Garcia-Pagan JC, Bosch J. Endoscopic band ligation in the treatment of portal hypertension. Nat Clin Pract Gastroenterol Hepatol 2005; 2: 526 35.

9. Planas R, Quer JC, Boix J, et al. A prospective randomized trial comparing somatostatin and sclerotherapy in the treatment of acute variceal bleeding. Hepatology 1994; 20: 370-5.

10. Besson I, Ingrand P, Person B, et al. Sclerotherapy with or without octreotide for acute variceal bleeding. N Engl J Med 1995; 333: 555-60.

11. D'Amico G, Politi F, Morabito A, et al. Octreotide compared with placebo in a treatment strategy for early rebleeding in cirrhosis. A double blind, randomized pragmatic trial. Hepatology 1998; 28: 1206-14.

12. D'Amico G, Criscuoli V, Fili D, et al. Meta-analysis of trials for variceal bleeding. Hepatology 2002: 36: 1023-4.

13. Sung JJ, Chung SC, Yung MY, et al. Prospective randomised study of efect of octreotide on rebleeding from oesophageal varices after endoscopic ligation. Lancet 1995; 346: 1666-9.

14. Stiegman GV, Goff JS, Michaletz-Onody PA, et al. Endoscopic sclerotherapy as compared with endoscopic ligation for bleeding esophageal varices. N Engl J Med 1992; 326: 1527-32. 